\title{
Sensorimotor Gating in Larval Zebrafish
}

\author{
Harold A. Burgess and Michael Granato \\ Department of Cell and Developmental Biology, University of Pennsylvania School of Medicine, Philadelphia, Pennsylvania 19104-6058
}

Control of behavior in the natural environment where sensory stimuli are abundant requires superfluous information to be ignored. In part, this is achieved through selective transmission, or gating of signals to motor systems. A quantitative and clinically important measure of sensorimotor gating is prepulse inhibition (PPI) of the startle response, impairments in which have been demonstrated in several neuropsychiatric disorders, including schizophrenia. Here, we show for the first time that the acoustic startle response in zebrafish larvae is modulated by weak prepulses in a manner similar to mammalian PPI. We demonstrate that, like in mammals, antipsychotic drugs can suppress disruptions in zebrafish PPI induced by dopamine agonists. Because genetic factors underlying PPI are not well understood, we performed a screen and isolated mutant lines with reduced PPI. Analysis of Ophelia mutants demonstrates that they have normal sensory acuity and startle performance, but reduced PPI, suggesting that Ophelia is critical for central processing of sensory information. Thus, our results provide the first evidence for sensorimotor gating in larval zebrafish and report on the first unbiased screen to identify genes regulating this process.

Key words: zebrafish; prepulse inhibition; behavior; sensorimotor gating; dopamine; startle response

\section{Introduction}

To survive in the natural environment, each individual needs to make appropriate motor decisions in response to the stream of sensory information arriving in different modalities. The problem is more acute for neonates, who must rely primarily on genetically defined neural circuits to first integrate sensory information and then select motor responses from a relatively limited repertoire. Neonatal behavior can nevertheless be surprisingly complex; previous observations have demonstrated that larval fish are able to navigate through hostile environments to return to their natal reef (Jones et al., 1999; Swearer et al., 1999), a feat likely to require the integration of multiple sensory systems (Kingsford et al., 2002). The relative simplicity of the nervous system in fish larvae offers an opportunity to study the neuronal basis of sensory integration without the confounding factor of learned behaviors.

The acoustic startle response is exquisitely modulated by environmental cues (Dawson et al., 1999), making it an attractive system for studying the cellular basis of behavioral regulation. Larval stage zebrafish display a robust startle response (supplemental movie 1, available at www.jneurosci.org as supplemental material), consisting of a "C-bend" of the body, followed by a smaller counter bend and swimming (Kimmel et al., 1974). The zebrafish startle response is mediated by reticulospinal neurons similar to the central elements underlying startle in higher vertebrates (Lingenhohl and Friauf, 1994; Liu and Fetcho, 1999;

\footnotetext{
Received 0ct. 3, 2006; revised March 20, 2007; accepted March 26, 2007.

This work was supported by a National Research Service Award postdoctoral fellowship to H.A.B. and National Institutes of Health Grants NS-048258 and MH-075691 to M.G. We thank Emma Mullins for cover art, Robert Smith for advice with electronics, and Jeremy Magland for programming support.

Correspondence should be addressed to Michael Granato at the above address. E-mail: granatom@mail.med.upenn.edu.

DOI:10.1523/JNEUROSCI.0615-07.2007

Copyright $\odot 2007$ Society for Neuroscience $\quad$ 0270-6474/07/274984-11\$15.00/0
}

Gahtan et al., 2002). In zebrafish, fast responses initiated with a C-bend (C-start responses) require just three bilateral pairs of reticulospinal neurons including the Mauthner cells (Liu and Fetcho, 1999). These cells receive multimodal sensory input (Zottoli et al., 1995) and have been previously suggested as a model for sensorimotor integration in the brainstem without the complication of corticospinal influences found in mammals (Eaton et al., 1991).

Prepulse inhibition (PPI) is a form of sensorimotor gating in which the startle response is attenuated when a weak nonstartling stimulus is presented shortly before the startling stimulus (Swerdlow et al., 2001). Impairments in PPI have been observed in several disorders including Huntington's disease (Swerdlow et al., 1995), Tourette's syndrome (Castellanos et al., 1996), and schizophrenia (Braff et al., 1978, 2001). Significantly, antipsychotic drugs reverse PPI deficits in schizophrenics (Kumari et al., 1999) and in animal models (Mansbach et al., 1988; Swerdlow et al., 1994; Geyer et al., 2001). Thus, interest has recently focused on deficits in PPI as a valuable endophenotype for genetic analysis of schizophrenia (Joober et al., 2002; Anokhin et al., 2003), although the molecular-cellular basis of PPI remains incompletely understood.

The availability of a zebrafish model for studying prepulse inhibition of the startle response would offer an opportunity to define the neural circuitry underlying a basic form of behavioral regulation and offer insights into neuropathological disease. We therefore sought to quantitatively define larval zebrafish responses to intense acoustic stimuli and determine whether any component of the response was modulated by weak prepulses in a manner similar to PPI.

\section{Materials and Methods}

Stimulus, imaging, and tracking. All movies were collected with a highspeed camera (Motionpro 2000; Redlake, Tucson, AZ) at 1000 frames/s 
at $512 \times 512$ resolution. Unless otherwise specified, larvae were studied in groups of 25-30 in $6 \mathrm{~cm}$ Petri dishes. Individual larvae were tested in 10-mm-diameter plastic O-rings attached to Petri dishes. The setup was otherwise identical to that used for testing larvae in groups. Adults were always studied individually in $10 \mathrm{~cm}$ diameter containers with $150 \mathrm{ml}$ of fish water. By raising the camera and using a wide-angle lens, thin male adults sufficiently resembled larvae to be tracked with minimal change to parameters.

Automated tracking software was written in the Interactive Data Language (IDL Visual Information Systems, Boulder, CO) and will be provided on request. We adapted the particle tracking algorithm of Crocker and Grier (1996) to identify and link the positions of each fish across video frames, and then performed a local density search to determine the orientation of the head segment. C-start responses were detected by changes in body orientation of $>16^{\circ}$ over a $3 \mathrm{~ms}$ window. As described below, startle responses occurred in two waves: short-latency C-start (SLC) responses and long-latency C-start (LLC) responses. After each experiment, we examined the latency histogram to find the center of the trough between the two waves of responses. This value was used to automatically distinguish between the responses. Similar to a previous report (Preuss and Faber, 2003), we found that startle response latency is significantly affected by temperature. Because experiments were performed at $23-27^{\circ} \mathrm{C}$, the cutoff latency between SLCs and LLCs varied from 13 and $18 \mathrm{~ms}$. We calculated LLC responsiveness as the number of larvae responding with long-latency C-bends as a fraction of all larvae still stationary after the first wave of SLC responses had initiated [percentage of LLC/remaining (LLC/R)]. This adjustment is necessary because larvae that execute SLC responses are no longer in the "pool" of larvae able to initiate an LLC response. Our finding that these responses are mediated by distinct neural pathways (see Results) supports this method of calculating LLC responsiveness. When testing individual larvae for PPI, animals that exhibited a startle response to $<30 \%$ of tap stimuli were classed as nonresponders and excluded from analysis, similar to procedure in human and animal studies of prepulse inhibition. For PPI, percent inhibition was calculated as $100 \times$ (percentage responding to startle stimulus - percentage responding to prepulse + startle sequence)/(percentage responding to startle stimulus), similar to the proportion of difference measure usually used in mammalian PPI studies (Blumenthal et al., 2004).

Three types of acoustic/vibrational stimulus were used. For studying PPI and startle responses to stimuli of varying intensity and frequency, we used a small vibration exciter (4810; Brüel and Kjaer, Norcross, GA), controlled by an digital-analog card (PCI-6221; National Instruments, Austin, TX) with timing and waveforms generated by custom software (available on request). Peak to peak acceleration was calculated by measuring the position of a fixed particle on the stimulating apparatus at 10,000 frames/s. This allowed us to verify that acceleration was linearly correlated with input voltage to the device. Unless otherwise specified, stimulus waveforms were $144 \mathrm{~m} / \mathrm{s}^{2}$, of 2 ms duration, and nominally 500 or $1000 \mathrm{~Hz}$, although such stimuli are intrinsically broadband. For screening, we use an impact "tap" stimulus delivered by a tubular solenoid (S-63-38-H; Magnetic Sensor Systems, Van Nuys, CA). When tap stimuli were used, prepulses were produced by a vibrating transducer (Taparia Magnetics, Mumbai, India) mounted on the light box used to illuminate the larvae. In all experiments, we delivered a $2 \mathrm{~ms}, 500 \mathrm{~Hz}$ vibration. Prepulse intensity was measured by a Checkmate cm-130 decibel meter (Galaxy Audio, Wichita, KS). Precise timing of activation of the camera and stimuli was achieved using a Stamp BS2SX microcontroller unit (Parallax, Rocklin, CA). In all experiments, startle-inducing stimuli were delivered at $15 \mathrm{~s}$ intervals, which pilot experiments determined were sufficient to prevent habituation (supplemental Fig. 1, available at www. jneurosci.org as supplemental material). Where different stimuli were presented within a single experiment, a randomized complete block design was used. In PPI experiments, prepulse trials were interleaved with stimulus alone trials in a pseudorandom order.

Laser ablations. Reticulospinal neurons were backfilled by pressure injection of a $50 \%$ solution of fluorescein-conjugated dextran $10 \mathrm{~K}$ (Invitrogen, Eugene, OR) in $10 \%$ Hanks solution, into the ventral spinal cord of $4 \mathrm{~d}$ postfertilization (dpf) larvae. After $24 \mathrm{~h}$, larvae were anesthe- tized with $0.03 \% 3$-aminobenzoic acid ethyl ester (Sigma, St. Louis, MO) and mounted dorsal side up in 3\% methylcellulose. Mauthner cells were visualized with $50 \mathrm{~W}$ fluorescence illumination on an upright compound microscope (Zeiss, Oberkochen, Germany). Laser ablation of Mauthner neurons was performed using a MicroPoint pulsed nitrogen laser (Photonic Instruments, St. Charles, IL) using a $63 \times$ water lens, pulsing cells for $20-30 \mathrm{~s}$ at $10 \mathrm{~Hz}$. For controls, randomly selected reticulospinal neurons labeled by the backfill procedure were ablated. After $2-5 \mathrm{~h}$, larvae were remounted and inspected. Similarly to Liu and Fetcho (1999), we found that after successful ablations, the Mauthner axon stump could be observed in the caudal hindbrain or spinal cord, whereas fluorescence returned to Mauthner neurons when ablation was unsuccessful. For bilateral ablations, larvae were individually tested with 60 acceleration stimuli, at 6 and $7 \mathrm{dpf}$, comprised of pseudorandomly interleaved 30 weak stimuli $\left(17 \mathrm{~m} / \mathrm{s}^{2}\right)$ and 30 intense stimuli $\left(144 \mathrm{~m} / \mathrm{s}^{2}\right)$. For unilateral ablations, larvae were tested at 6 and $7 \mathrm{dpf}$ with 100 intense stimuli in total. Immediately after, larvae were fixed overnight at $4^{\circ} \mathrm{C}$ in $4 \%$ paraformaldehyde and stained with $3 \mathrm{~A} 10$ antibody (1:50; kind gift from Dr. T. Jessell, Columbia University, New York, NY) (Hatta, 1992) followed by goat anti-mouse IgG alexa-594 (Invitrogen) to provide an additional confirmation of successful Mauthner cell ablation (see Fig. 4F-I).

Pharmacology. Apomorphine (A4393; Sigma) and ketamine (kind gift from Dr. S. Kanes, University of Pennsylvania, Philadelphia, PA) were dissolved directly in E3 medium and used immediately. Haloperidol (H1512; Sigma) was dissolved in DMSO and DMSO was used as a vehicle control where appropriate. All experiments were done in groups of 30 larvae at $6 \mathrm{dpf}$. For PPI experiments, groups were tested $10 \mathrm{~min}$ after addition of buffer or drug to the water. Each group was probed with 20 startle alone stimuli and 20 sets of the startle stimulus preceded by a prepulse of intermediate intensity $(2 \mathrm{~ms}, 500 \mathrm{~Hz},+2.8 \mathrm{~dB})$. A $500 \mathrm{~ms}$ interstimulus interval was used in drug trials, except for ketamine, as discussed in the text.

Statistical analysis was performed using Microsoft (Redmond, WA) Excel and SPSS (Chicago, IL) 12.0. F scores were derived from single, two-factor, or repeated-measures ANOVA analysis as specified, and significant results followed by Bonferroni-corrected $t$ tests between groups are indicated in the text.

Zebrafish husbandry and mutagenesis. Zebrafish were raised and maintained as described by Mullins et al. (1994). Larvae were raised at $28^{\circ} \mathrm{C}$ in E3 medium with regular water changes. All larvae in Figures 1-6 were Tuebingen long-fin (TLF) strain zebrafish. We examined other strains, including $\mathrm{AB}$, Wik, and $\mathrm{Tu}$, and found that, although larvae show similar kinematics and PPI, startle responsiveness varies widely between strains. Mutagenesis was performed on males of $\mathrm{Tu}$ and $\mathrm{AB}$ strains according to the scheme outlined by Dosch et al. (2004). Because our screen was for mutants with reduced PPI, we used an intense prepulse $(50 \mathrm{~ms}, 80 \mathrm{~Hz}$, $+13.6 \mathrm{~dB}$ ), shown in pilot experiments to elicit $\sim 70 \%$ inhibition.

\section{Results \\ Larval zebrafish exhibit two types of startle response to acoustic stimuli}

The difficulty of manual or even semiautomated tracking has meant that previous descriptions of the larval zebrafish startle response were based on a relatively small number of events. Because we aimed to systematically measure subtle changes in the frequency and expression of startle responses, it was necessary to develop tracking software able to automatically record and quantify very large numbers of events. We therefore adapted a multiparticle tracking algorithm for analyzing high-speed video recordings of zebrafish larvae (Fig. 1A and supplemental movie 2, available at www.jneurosci.org as supplemental material). We added functionality for determining particle curvature, enabling us to quantitatively describe the kinematics of individual fish in response to a stimulus. By recording larvae in groups of 30, we could analyze $\sim 2500$ responses per hour, yielding information describing the latency, turn angle, angular velocity and duration of startle responses, and kinematics of subsequent bouts of swim- 
ming (Fig. $1 B$ ). Startle kinematics measured by automated analysis have very similar means and SDs to manually measured responses, demonstrating that the system is not only accurate, but recognizes startle responses despite behavioral variability (Table 1).

Measurement of 20,000 startle responses performed by $6 \mathrm{dpf}$ larvae revealed that acoustic startle responses are initiated in two discrete waves, distinguished by the latency of the response (Fig. 2A). Significant differences in the kinematic properties of C-bends initiated in the two waves suggest that these represent distinct behaviors (Fig. $2 B, D$ ). Responses in the first wave are initiated within $5.3 \pm$ $2.0 \mathrm{~ms}$ of the stimulus (mean $\pm \mathrm{SD}$ ) and have explosive fast-velocity C-bends with an invariant bend duration of 7-8 $\mathrm{ms}$. These short-latency C-starts (SLCs) are very similar to startle responses described previously in the literature (Kimmel et al., 1980; Liu and Fetcho, 1999). In contrast, the long-latency C-starts (LLCs) initiated in the second wave of responses, starting $28.2 \pm 8.9 \mathrm{~ms}$ after the stimulus, have a longer duration, but slower angular velocity, and achieve a somewhat smaller bend angle. However, as the angle traversed during the counter bend of LLCs is also smaller, the final direction of movement relative to the initial orientation of the larvae is very similar to that achieved during SLCs (Fig. $2 B$, Trajectory). LLC responses are produced by larvae tested individually, excluding the possibility that they are provoked by the movement of larvae in the first wave (Fig. 2C). These responses constitute a novel secondary startle behavior in zebrafish larvae.

We next asked whether SLC and LLC responses are differentially modulated by stimulus properties. Indeed, LLCs are preferentially elicited by low-intensity stimuli. Intriguingly, SLC performance was probabilistic: response frequency grew as stimulus intensity increased (Fig. $3 A$ ), but the average kinematic performance of the C-bend remained unchanged (Fig. $3 B)\left(F_{(5,28)}=2.1 ; p=0.1\right)$. SLC startle responses are therefore "all-ornothing" responses with respect to stimulus intensity. In contrast, mean LLC performance was graded according to stimulus intensity, indicating that different neural mechanisms support the two behaviors (Fig. $3 B)\left(F_{(6,34)}=5.0 ; p=0.001\right)$. The longer latency but more reliable execution of LLCs is suggestive of a "backup" startle mechanism. Consistent with this, when startle stimuli are presented in rapid succession, SLC responsiveness quickly declines much more rapidly than LLC responsiveness. After $20 \mathrm{~s}$ of repetitive stimuli, SLC responses are nearly abolished, whereas LLCs are robustly evoked even after a series of 60

B
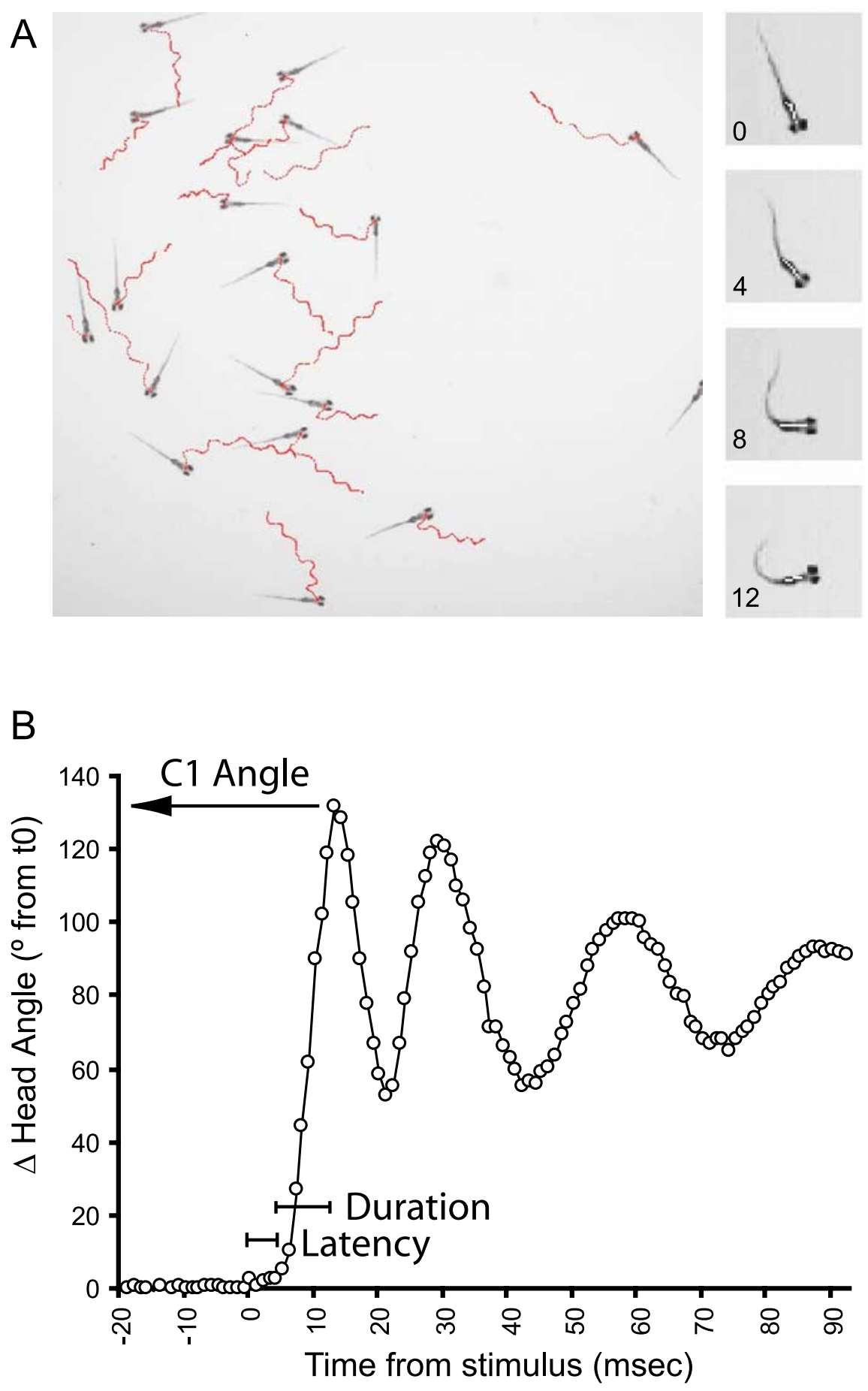

Figure 1. High throughput analysis of acoustic startle responses in zebrafish larvae. $\boldsymbol{A}$, Behavioral tracking of multiple larvae. The positions of 18 zebrafish larvae ( $6 \mathrm{dpf}$ ) are shown in red tracks over 120 frames in response to an acoustic/vibrational stimulus (left). The vertical series (right) shows the startle response of a single larva, with the bar along the head segment indicating the orientation of the fish. $\boldsymbol{B}$, Analysis of head orientation permits automated identification and measurement of responses. Response latency, $(1$ angle, and C1 duration are quantified as indicated.

intense stimuli (Fig. 3C). The decline in SLC responsiveness is not accompanied by a drop in the magnitude of C-bends, further demonstrating that SLC responses are all-or-nothing events (Fig. $3 C$, inset). Reticulospinal neurons controlling startle responses in lamprey are modulated during swimming (Currie and Carlsen, 1987). We therefore asked whether ongoing locomotion modulates SLC or LLC responsiveness. Motor activity potently enhances SLC responsiveness (Fig. 3D) (two-way ANOVA, main 
Table 1. Automated versus manual measurement of startle

\begin{tabular}{llll}
\hline & Latency $(\mathrm{ms})$ & Duration $(\mathrm{ms})$ & C1 angle $\left(^{\circ}\right)$ \\
\hline Manual & $10.5 \pm 10.1$ & $7.2 \pm 2.5$ & $110 \pm 21$ \\
Tracked & $11.0 \pm 11.0$ & $7.7 \pm 2.2$ & $110 \pm 17$ \\
Difference & $0.66 \pm 1.4$ & $1.3 \pm 1.5$ & $7.7 \pm 10.1$ \\
\hline
\end{tabular}

Fifty startle responses from a video recording of day 6 larvae were assessed first manually, then using automated tracking software. In all cases, automated tracking identified the initiation of startle responses. Measurements were made of latency to initiation of startle, bend angle during the first phase of the C-start, and duration of the first phase of the C-start. Automated and manual measurements show very similar means and SDs. The average absolute difference between the measurements is small for all parameters, demonstrating that automated tracking can reliably identify startle responses.

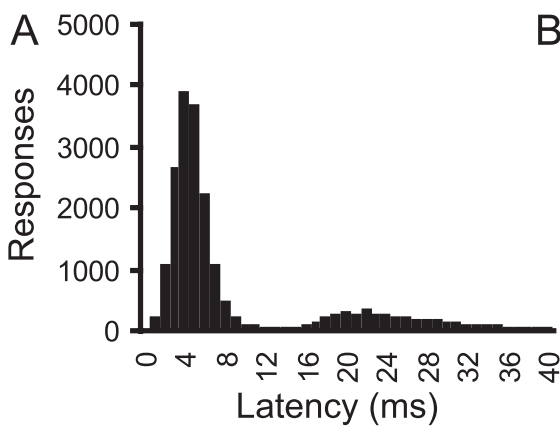

C

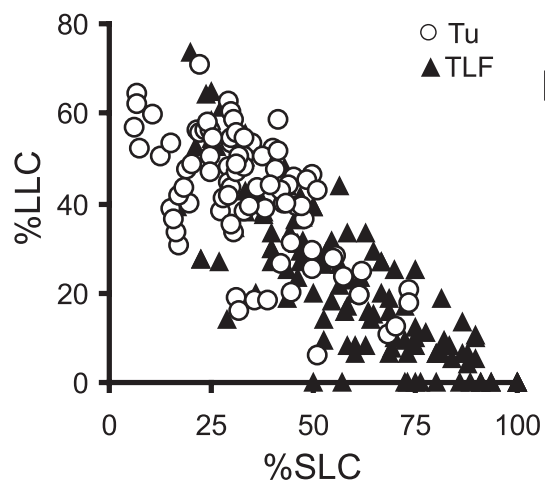

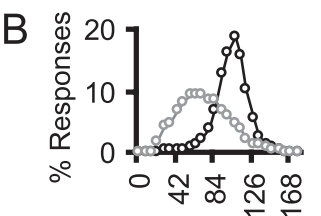

C1-Bend Angle ( ${ }^{\circ}$ )

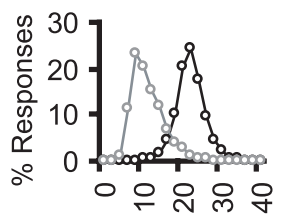

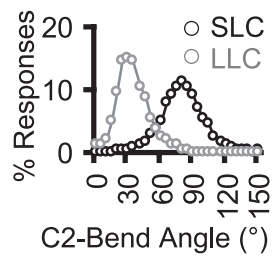

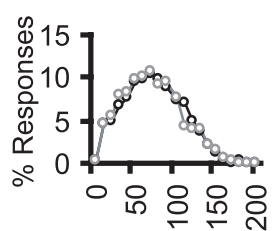
Max Ang.Vel. $\left({ }^{\circ} / \mathrm{ms}\right) \quad$ Escape Trajectory $\left({ }^{\circ}\right)$

\begin{tabular}{|l|l|l|l|l|}
\cline { 2 - 5 } \multicolumn{1}{c|}{} & $\begin{array}{l}\text { Latency } \\
(\mathrm{ms})\end{array}$ & $\begin{array}{l}\text { C1- } \\
\text { Angle }\left({ }^{\circ}\right)\end{array}$ & $\begin{array}{l}\text { C1- } \\
\text { Duration } \\
(\mathrm{ms})\end{array}$ & $\begin{array}{l}\text { C1-Max } \\
\text { Angular } \\
\text { Vel. }\left({ }^{\circ} / \mathrm{ms}\right)\end{array}$ \\
\hline SLC & $5.3 \pm 2.0$ & $105 \pm 18$ & $7.5 \pm 1.4$ & $22.5 \pm 4.1$ \\
\hline LLC & $28.2 \pm 9.0$ & $75 \pm 28$ & $12.8 \pm 4.0$ & $11.8 \pm 4.6$ \\
\hline
\end{tabular}

\begin{tabular}{|l|l|l|l|}
\cline { 2 - 4 } \multicolumn{1}{c|}{} & $\begin{array}{l}\text { C2- } \\
\text { Angle }\left({ }^{\circ}\right)\end{array}$ & $\begin{array}{l}\text { C2- } \\
\text { Duration } \\
(\mathrm{ms})\end{array}$ & $\begin{array}{l}\text { C2-Max } \\
\text { Angular } \\
\text { Vel. }\left({ }^{\circ} / \mathrm{ms}\right)\end{array}$ \\
\hline SLC & $82 \pm 21$ & $8.4 \pm 3.8$ & $17.2 \pm 4.3$ \\
\hline LLC & $37 \pm 16$ & $11.8 \pm 3.9$ & $6.8 \pm 3.3$ \\
\hline
\end{tabular}

Figure 2. Latency histograms for acoustic startle responses in zebrafish larvae are biphasic. $\boldsymbol{A}$, Histogram of the latency to response for 19,993 startle trials. Whereas $78.6 \%$ of responses were initiated within $12 \mathrm{~ms}$, remaining responses were initiated in a "second wave," with a peak at $22 \mathrm{~ms}$. All trials in this figure were conducted using a constant tap stimulus. $\boldsymbol{B}$, Histograms of response kinematics and movement trajectories for short-latency responses (black) and long-latency responses (gray). C, Larvae tested individually with 30 trials per fish produced both SLC and LLC responses. Both TLF (triangles; $n=127$ ) and Tu strain larvae (circles; $n=90$ ) were capable of the two types of startle response. D, Kinematic parameters for short-latency C-bend $(n=5108)$ and long-latency C-bend $(n=2778)$ responses to acoustic startle stimuli (mean \pm SD). Two-tailed $t$ tests and significant differences for all parameters are presented, with $p$ values $<10^{-20}$. Ang. Vel., Angular velocity.

effect of movement, $\left.F_{(1,368)}=206.8, p<0.001\right)$, but reduces LLC responses (Fig. 3E) (two-way ANOVA, main effect of movement, $\left.F_{(1,296)}=38.7, p<0.001\right)$, indicating differential sensorimotor control of the two behaviors. Finally, we asked whether SLCs and LLCs are mediated by different components of the auditory apparatus. Anterior and posterior otoliths are missing in keinstein mutant fish (Whitfield et al., 1996). In keinstein mutants, LLCs were completely abolished at all stimulus frequencies (Fig. 3G), whereas SLCs were evoked normally at low frequencies but less efficiently at high frequencies (Fig. $3 F$ ). Together, these results demonstrate that there are two distinct behaviors in the response repertoire of zebrafish larvae to acoustic startle stimuli, which are variably modulated by the sensory environment.

\section{Mauthner cells are required for SLC but not LLC responses}

Previous work has demonstrated that the Mauthner cell is necessary in zebrafish larvae for high performance responses to tailThe other two cases had very low angular velocities consistent with spontaneously initiated movements. Unilateral ablation did not lateralize LLCs (Fig. 4D). Detailed analysis of LLC kinematics in the bilateral Mauthner ablated larvae demonstrated no significant differences from control larvae, arguing that the Mauthner cell is not involved in this response (Fig. 4E). Together, these experiments show that the Mauthner cell is required for SLC responses to acoustic stimuli and that the responses remaining after Mauthner ablation are normal LLC responses.

\section{Prepulse inhibition of SLC startle responses}

Our finding that zebrafish larvae have two distinct modes of startle response mediated by different neural elements and differentially modulated by the sensory environment prompted us to ask whether a process similar to mammalian prepulse inhibition can also modulate startle responses in zebrafish larvae. We used a two-pulse paradigm in which the intense startle inducing stimu- 
lus was sometimes preceded by an identical but weaker waveform. Weak prepulses were $-20,-30$, or $-40 \mathrm{~dB}$ relative to the intense stimulus and presented $300 \mathrm{~ms}$ earlier. Startle responses were significantly inhibited by prepulses. This was manifest as a reduction in the fraction of larvae responding in the four stimulus conditions (Fig. $5 A)\left(F_{(3,44)}=6.2 ; p=0.0013\right)$ with significant inhibition obtained for even the weakest prepulse $\left(p=1.1 \times 10^{-4}\right.$, paired two-tailed $t$ test). In contrast, no change in LLC responsiveness was observed (Fig. $5 B)\left(F_{(3,44)}=0.27 ; p=0.84\right)$. Larvae tested individually also showed robust inhibition of SLC responsiveness (Fig. 5D). This demonstrates that a process similar to prepulse inhibition is present in larval zebrafish and differentially modulates the two forms of startle behavior.

In mammals, weak prestimuli reduce the magnitude of subsequently evoked startle responses (Dawson et al., 1999). However, analysis of zebrafish startle kinematics revealed that the only consistent effect of a weak antecedent prepulse was to slightly delay the initiation of the startle response (Fig. $5 C$, Table 2). No effect was seen on the angular velocity $(t=1.13 ; \mathrm{df}=$ $4960 ; p=0.26)$ or, more importantly, on the magnitude of the $\mathrm{C}$-bend $(t=0.089$; $\mathrm{df}=4960 ; p=0.93)$. Interestingly, LLC startle kinematics were also unchanged. Because LLC responsiveness and kinematic performance are smaller in response to weaker stimuli, this argues that prepulses do not reduce sensory acuity, but rather modulate sensorimotor integration for SLCs.

The demonstration that PPI in mammals is maximally effective at interstimulus intervals between 15 and $400 \mathrm{~ms}$ (Braff et al., 1978; Mansbach and Geyer, 1991)

has provided crucial clues as to the neural substrate of the inhibitory circuit (Swerdlow and Geyer, 1999). We therefore measured inhibition while systematically varying the interval between the prepulse and the stimulus (Fig. 5E). Inhibition was absent at a lead interval of $10 \mathrm{~ms}$, but present at $30 \mathrm{~ms}$, arguing that as in mammals, a polysynaptic pathway mediates PPI. However, whereas interstimulus intervals of $>800 \mathrm{~ms}$ typically facilitate startle responses in mammals (Putnam and Vanman, 1999), we saw no similar process in zebrafish larvae at long lead intervals.

Finally, we asked whether startle inhibition in zebrafish is developmentally restricted. As in rats, where PPI can be demonstrated at the onset of auditory acuity (Parisi and Ison, 1979), we could elicit inhibition in larvae as young as $3 \mathrm{dpf}$, when occasional acoustic startle responses can first be elicited (data not shown). We found robust PPI across a range of developmental stages, persisting into adulthood. Startle responses in adult fish typically occur within $20 \mathrm{~ms}$ of an acoustic/vibrational stimulus (Eaton et al., 1981). Using a vibrational stimulus, we found similar results, with modal latency to startle being $8 \mathrm{~ms}$ (Fig. $5 F$, inset). In con- trast to larvae, there was no discrete long latency wave of responses with a characteristic kinematic profile (Fig. $5 F$ ). Weak prepulses clearly reduced startle responsiveness in adult fish (Fig. $5 G)\left(F_{(3,55)}=6.4 ; p=0.0008\right)$ and, as in larvae, inhibition was proportional to the intensity of the prepulse. PPI in adults varied between 29 and $72 \%$ and was maximal at an interstimulus interval of $50 \mathrm{~ms}$ (Fig. $5 H)\left(F_{(4,70)}=2.93 ; p=0.026\right)$.

\section{Dopaminergic and glutamatergic modulation of prepulse inhibition}

Zebrafish larvae readily absorb a wide range of chemicals, making them an ideal model for analyzing pharmacological modulation of behavior (Goldsmith, 2004). We exploited this advantage to investigate whether prepulse inhibition in zebrafish is regulated by the same neurotransmitter systems as in mammals. In mammals, PPI is disrupted by agents that antagonize NMDA receptor function (Mansbach and Geyer, 1989, 1991) or augment dopamine signaling (Mansbach et al., 1988; Linn et al., 2003; RalphWilliams et al., 2003). Because leading hypotheses for the patho- 
A

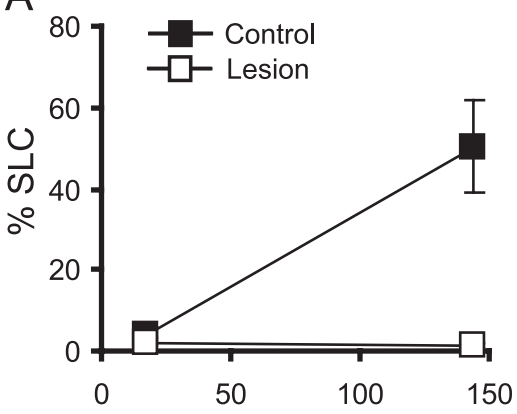

Stimulus Intensity $\left(\mathrm{m} / \mathrm{sec}^{2}\right)$

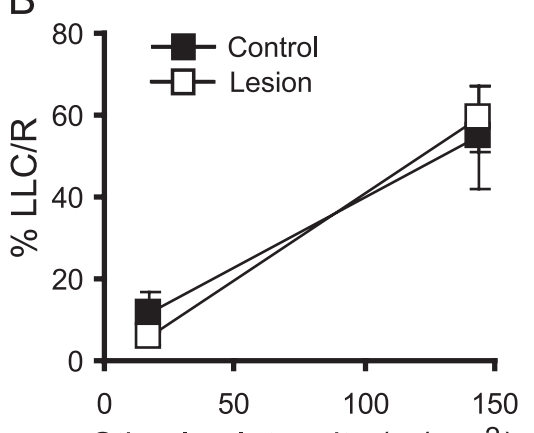

C
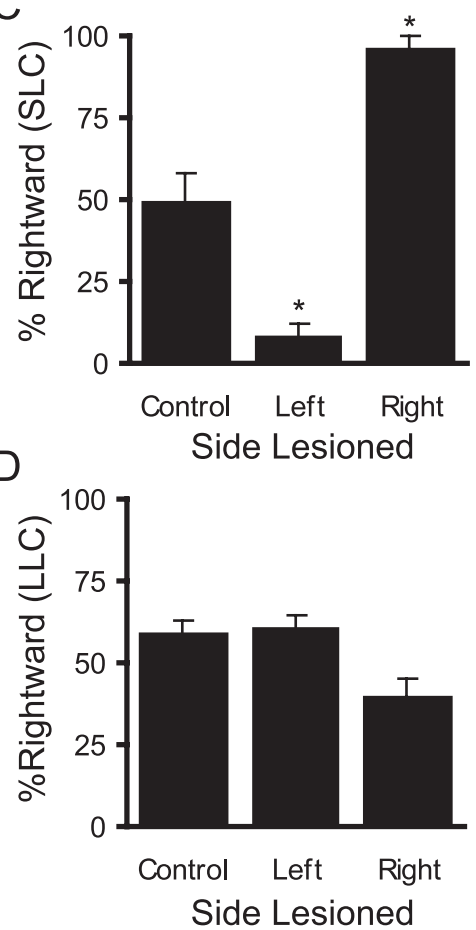

Side Lesioned
E
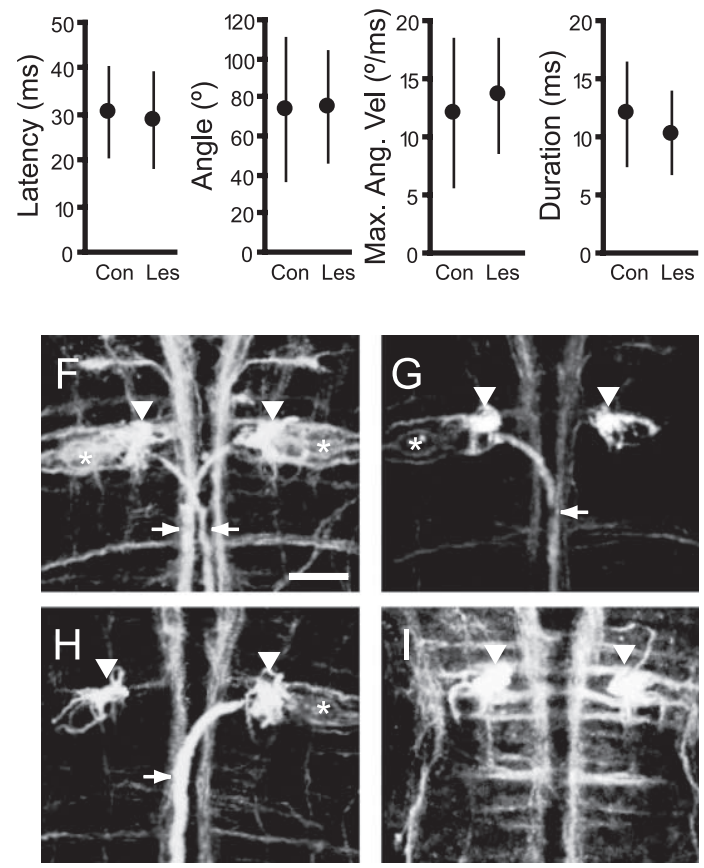

Figure 4. Mauthner cells are required for short-but not long-latency startle responses. $\boldsymbol{A}$, Bilateral ablation of the Mauthner cells abolishes SLC responses in lesioned larvae (Lesion; $n=7$ ). Robust SLC responsiveness is retained after ablation of other randomly selected, reticulospinal neurons (Control; $n=9$ ). Larvae were tested with 60 trials ( 30 trials at each stimulus intensity, interleaved in a pseudorandom sequence) at 24 and $48 \mathrm{~h}$ after lesioning. Graph shows mean responsiveness for each group. Error bars indicate SEM. $\boldsymbol{B}$, In the same experiment as in $\boldsymbol{A}$, the two groups of larvae show nearly identical LLC responsiveness at both stimulus intensities. C, After unilateral ablation of one Mauthner cell, larvae produce SLC responses almost exclusively on the side ipsilateral to the ablation. Each larva was tested with a series of one hundred stimuli. We calculated the percentage of SLC responses that were initiated with a rightward C-bend. For control larvae (Control; $n=13$ ), an average of $49.5 \%$ of responses were initiated in a rightward direction, indicating no directional bias. In contrast, only $7.7 \%$ of SLCs were right-directed in left Mauthner lesioned larvae (Left; $n=$ 11 ; two-tailed $t$ test, $p=0.0014$ vs control), whereas $96.3 \%$ of SLCs were right-directed in right Mauthner lesioned larvae (Right; $n=9 ;$ two-tailed $t$ test, $p=4.6 \times 10^{-4}$ vs control). ${ }^{*} p<0.01$ versus control. $\boldsymbol{D}$, In the same experiment as in $\boldsymbol{C}$, LLC responses made by lesioned larvae do not show directional bias. The slight reduction seen in rightward turns for right-lesioned larvae was neither significant (two-tailed $t$ test, $p=0.067$ vs control) nor reproducible in other experiments. $\boldsymbol{E}$, Bilateral ablation of Mauthner cells does not affect the kinematics of LLC responses. LLC latency, bend angle, angular velocity (Max. Ang. Vel), and duration are almost identical in lesioned larvae (Les) and controls (Con). Kinematic data are taken from the experiment described in $\boldsymbol{A}$. Graphs show the mean and SD. F-I, Confocal analysis was used to confirm complete ablation of the Mauthner cells. In wild-type larvae $(\boldsymbol{F})$, both Mauthner cell bodies (each marked with an asterisk) and axons (arrows) are visible. The axon cap which is comprised of fibers from other neurons is also visible (arrowheads). In right Mauthner lesioned larvae ( $\boldsymbol{G}$ ), only the left Mauthner cell and axon remain. Both axon caps are clearly stained demonstrating that laser ablation has selectively killed the right Mauthner cell. Conversely, in left Mauthner ablations ( $\boldsymbol{H})$, only the right Mauthner cell and axon are visible. After bilateral ablation (I), neither Mauthner cell body or axon are stained. Scale bar, $20 \mu \mathrm{m}$.

physiology of schizophrenia posit disruptions in these two neurotransmitter systems (for review, see Laruelle et al., 2003), considerable interest has focused on animal models in which PPI is disrupted by prodopaminergic or antiglutamatergic drugs.

Reversal of the PPI deficits induced by the dopamine agonist apomorphine is a well validated model for investigating the efficacy of antipsychotic compounds (Swerdlow et al., 1994). Apomorphine suppressed prepulse inhibition of startle in larval zebrafish (Fig. 6A) $\left(F_{(3,13)}=10.3 ; p=9.6 \times 10^{-4}\right)$ without effecting baseline SLC responsiveness $\left(F_{(3,13)}=1.9 ; p=0.18\right)$. Startle probability on PPI trials was increased $\left(F_{(3,13)}=3.4 ; p=\right.$ $0.05)$, confirming that apomorphine reduces sensorimotor gating. Previous exposure to the antipsychotic drug haloperidol, a dopamine D2 receptor antagonist, significantly attenuated the apomorphine induced deficit (Fig. 6B) (two-factor ANOVA, significant main effect of apomorphine, $F_{(1,35)}=9.9, p=0.003$; significant apomorphine by haloperidol interaction, $F_{(2,35)}=3.3$, $p=0.03$ ). A variety of antipsychotic drugs, including haloperidol facilitate baseline PPI in rodents (Depoortere et al., 1997; Ouagazzal et al., 2001). High doses of haloperidol also potentiate baseline inhibition in zebrafish larvae (Fig. $6 C)\left(F_{(2,21)}=21.8 ; p=\right.$ $\left.7.6 \times 10^{-6}\right)$ without altering baseline startle $\left(F_{(2,21)}=0.40 ; p=\right.$ $0.67)$. Haloperidol reduced startle responsiveness on prepulse trials $\left(F_{(2,21)}=7.4 ; p=0.004\right)$ confirming that sensorimotor gating is augmented. These data demonstrate that dopamine D2 receptors play a central role in modulating startle inhibition in zebrafish and suggests that a key clinical assay for investigating antipsychotic efficacy may plausibly be extended to nonmammalian vertebrates.

Sensorimotor gating deficits in schizophrenic patients have also been modeled by inducing PPI deficits through disruptions in NMDA signaling. NMDA antagonists differentially modulate PPI in mammals depending on the interstimulus interval (Curzon and Decker, 1998; Schall et al., 1999; Linn and Javitt, 2001). At short lead intervals, ketamine potentiates PPI in humans (Duncan et al., 2001; Abel et al., 2003), but can eliminate or reverse PPI in rats (Mansbach and Geyer, 1991). We therefore tested the effect of ketamine on prepulse inhibition at both short (30 ms) and medium (500 ms) interstimulus intervals. At the short lead interval, ketamine significantly augmented inhibition (Fig. $6 D)\left(F_{(3,22)}=15.5 ; p=1.2 \times 10^{-5}\right)$ with reduced startle probability on prepulse trials $\left(F_{(3,22)}=13.2 ; p=3.8 \times 10^{-5}\right)$, indicating an effect on sensorimotor gating. Conversely, at the $500 \mathrm{~ms}$ interval, ketamine disrupted inhibition (Fig. 6E) $\left(F_{(3,20)}=8.3 ; p=8.7 \times 10^{-4}\right)$, causing increased startle responsiveness on prepulse trials $\left(F_{(3,20)}=39.6 ; p=1.3 \times 10^{-8}\right)$. Ket- 
amine sometimes slightly reduced baseline startle although this effect was not consistently obtained. The similarity of pharmacological effects on prepulse inhibition in fish and mammals suggests a conserved role for dopaminergic and glutamatergic regulation of PPI. Moreover, it argues that important elements of neural circuits which modulate this process are already established in $6 \mathrm{dpf}$ zebrafish larvae.

\section{Prepulse inhibition mutant screen}

Although mouse lines with defects in PPI have been described (Geyer et al., 2002), no unbiased genetic screens for PPI mutants have been reported. Analysis of mutants obtained from such screens have yielded striking insights into the molecular and cellular basis of behavior in invertebrates (Sokolowski, 2001; Anholt and Mackay, 2004). Our surprising finding that prepulse inhibition robustly modulates startle responsiveness in larvae as young as $6 \mathrm{dpf}$ made it feasible to undertake a genetic mutant screen.

Behavioral phenotypes are often variably penetrant on different genetic backgrounds, greatly complicating mapping and cloning of mutants. We therefore used ethylnitrosourea to mutagenize males of two strains, $\mathrm{Tu}$ and $\mathrm{AB}$, and implemented a breeding scheme to ensure that the F3 offspring screened were of mixed genetic background, suitable for molecular genetic mapping (Dosch et al., 2004). Nine larvae per F3 clutch were tested simultaneously, but in separate wells (supplemental movie 2, available at www.jneurosci.org as supplemental material), enabling us to exclude individuals with reduced startle responsiveness, obvious morphological defects, or abnormal startle kinematics. We used an intense prepulse that yielded $73 \pm 13 \%$ inhibition (mean $\pm \mathrm{SD}$ ) in wild-type larvae. When individuals with less than three SDs from the mean (30\% PPI) were identified, we tested 18 more larvae from the same cross to determine whether mutants were present in approximately Mendelian ratios. Positive families were raised and retested in the following generation. Of 686 genomes screened, we reconfirmed five independent mutant lines for which the reduced PPI phenotype persisted in the F4 generation.

To validate our strategy, we characterized one mutant line in more detail. In clutches derived from ophelia heterozygotes, 27\% (15 of 55) larvae have reduced inhibition, consistent with a recessive mode of inheritance (Fig. 7A, bottom). In
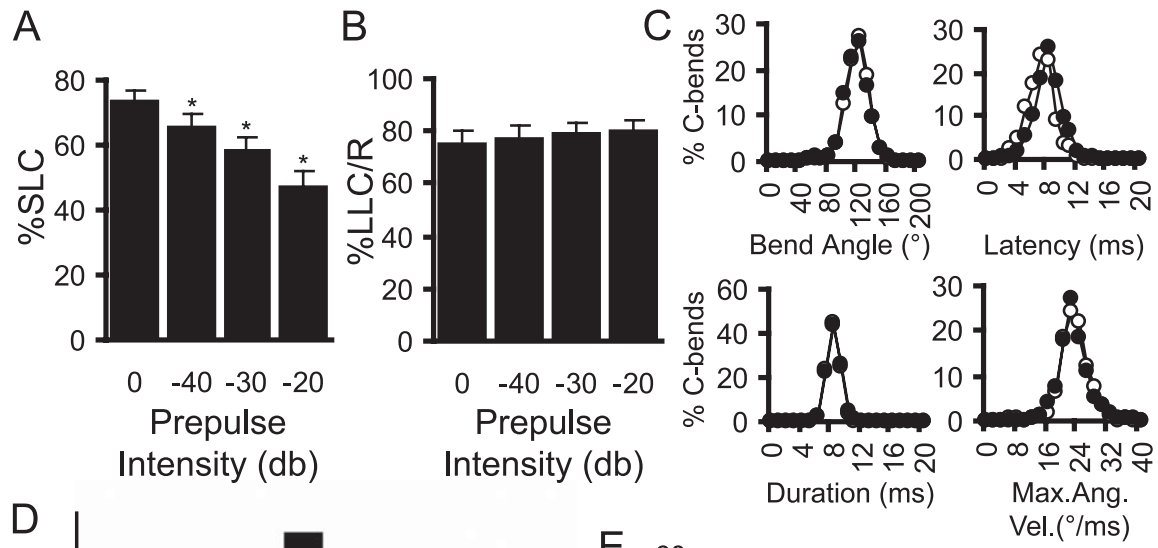

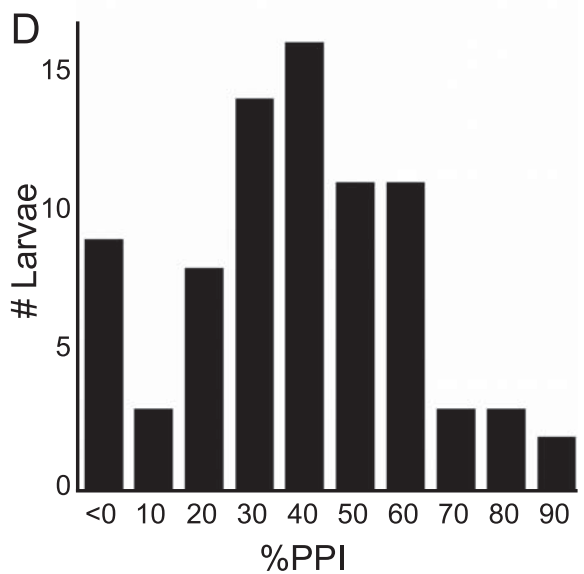

$\mathrm{F}$

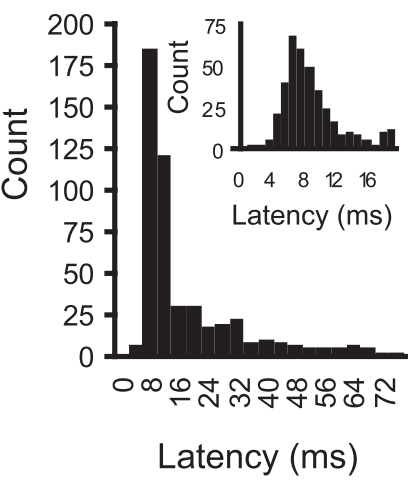

G

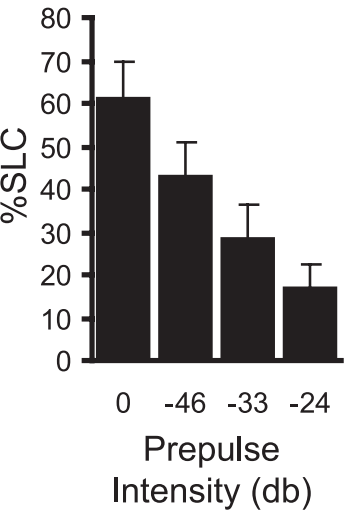

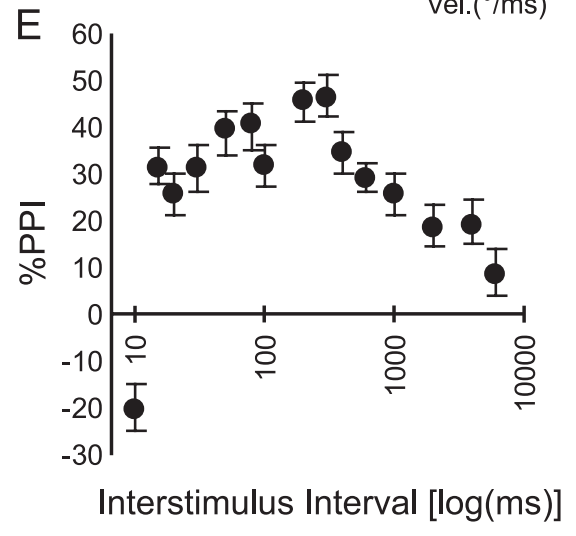

$\mathrm{H}$
Figure 5. Prepulse inhibition of the startle response in zebrafish. $A, A$ weak prepulse reduces the fraction of larvae responding to a subsequent startle-inducing stimulus. Groups of larvae $(n=12)$ were exposed to 15 repeats of each of four conditions (startle stimulus alone, or preceded by identical but weaker stimuli with magnitude relative to the startle stimulus as indicated). SLC responses are significantly reduced at all prepulse intensities relative to stimulus-alone trials $\left({ }^{*} p<0.001\right) \boldsymbol{B}$, LLC responses are not reduced in frequency by presentation of a prepulse. $C$, The prepulse stimulus does not alter the magnitude of the startle response. Histograms show the kinematic profile for 1000 C-bend responses to a startle stimulus (open circles) and 815 C-bend responses of the same larvae to prepulse plus stimulus trials (filled circles). Startle latency shows a small but significant delay in prepulse trials $\left(F_{(1,1813)}=127 ; p<10^{-7}\right.$, one-way ANOVA), whereas histograms for other kinematic parameters are completely overlapping. Max. Ang. Vel., Maximum angular velocity. D, PPI is also exhibited by individual larvae. 0 f 80 larvae, robust inhibition of startle is present in all but nine fish. Four of the nine had unusually high or low SLC responsiveness ( $>95$ or $<30 \%$ respectively), suggesting that the lack of inhibition measured may have been attributable to ceiling and floor effects, respectively. $\boldsymbol{E}$, The extent of the inhibition elicited by a prepulse varies with the interval between the prepulse and the tap stimulus. Groups of larvae $(n=29)$ were subjected to a startle stimulus alone, and the startle stimulus preceded by the prepulse at each of the indicated intervals. Inhibition was maximal at 300 ms. $\boldsymbol{F}$, Latency histogram for startle responses in adult fish (TLF males, 1.5-2 years old) shows a single-tailed distribution different from the biphasic latency histogram for larvae (Fig. $2 \mathrm{~A}$ ). Additional analysis of long-latency responses did not reveal a distinct kinematic profile similar to larvae. Inset, Histogram of short-latency responses ( $<20 \mathrm{~ms}) \mathbf{G}$, Preceding a startle stimulus with weak prepulses of indicated relative intensity reduces startle responsiveness in adults. $\boldsymbol{H}$, Analysis of startle inhibition when the prepulse preceded the startle stimulus at the indicated intervals. Reduced startle responsiveness compared with the no prepulse condition is significant only at the 50 and 300 ms interstimulus intervals ( $p=1.0 \times 10^{-4}$ and $p=0.014$ respectively, two-tailed paired $t$ test). Error bars indicate mean percent $\mathrm{PPI} \pm \mathrm{SEM}$. 
Table 2. Startle kinematics are not effected by prepulse inhibition

\begin{tabular}{|c|c|c|c|c|c|c|c|c|}
\hline \multirow{2}{*}{$\bar{P}$} & \multicolumn{4}{|l|}{ SLC } & \multicolumn{4}{|l|}{ LLC } \\
\hline & $\begin{array}{l}\text { Latency } \\
\text { (ms) }\end{array}$ & $\begin{array}{l}\mathrm{C} 1 \text { angle } \\
\left({ }^{\circ}\right)\end{array}$ & $\begin{array}{l}\text { Duration } \\
\text { (ms) }\end{array}$ & $\begin{array}{l}\text { Ang vel } \\
(\% / m s)\end{array}$ & $\begin{array}{l}\text { Latency } \\
\text { (ms) }\end{array}$ & $\begin{array}{l}\text { C1 angle } \\
\left({ }^{\circ}\right)\end{array}$ & $\begin{array}{l}\text { Duration } \\
\text { (ms) }\end{array}$ & $\begin{array}{l}\text { Ang vel } \\
(\% / \mathrm{ms})\end{array}$ \\
\hline Startle & $7.0 \pm 0.8$ & $110 \pm 6$ & $8.1 \pm 0.5$ & $22.0 \pm 1.4$ & $27.7 \pm 2.8$ & $81 \pm 13$ & $12.6 \pm 1.2$ & $12.0 \pm 2.2$ \\
\hline PPI & $8.3 \pm 0.6^{*}$ & $109 \pm 5$ & $8.1 \pm 0.4$ & $21.7 \pm 1.5$ & $29.2 \pm 2.9$ & $75 \pm 7$ & $12.1 \pm 1.2$ & $11.3 \pm 1.2$ \\
\hline
\end{tabular}

Startle kinematics for SLCs and LLCs during responses to stimulus alone or to stimulus preceded by a $-40 \mathrm{~dB}$ prepulse (mean $\pm S D$ ). Only the latency of SLC responses is significantly different $\left({ }^{*} p=1.1 \times 10^{-7}\right.$, paired $t$ test), whereas other kinematic parameters are not changed. Ang vel, Angular velocity.
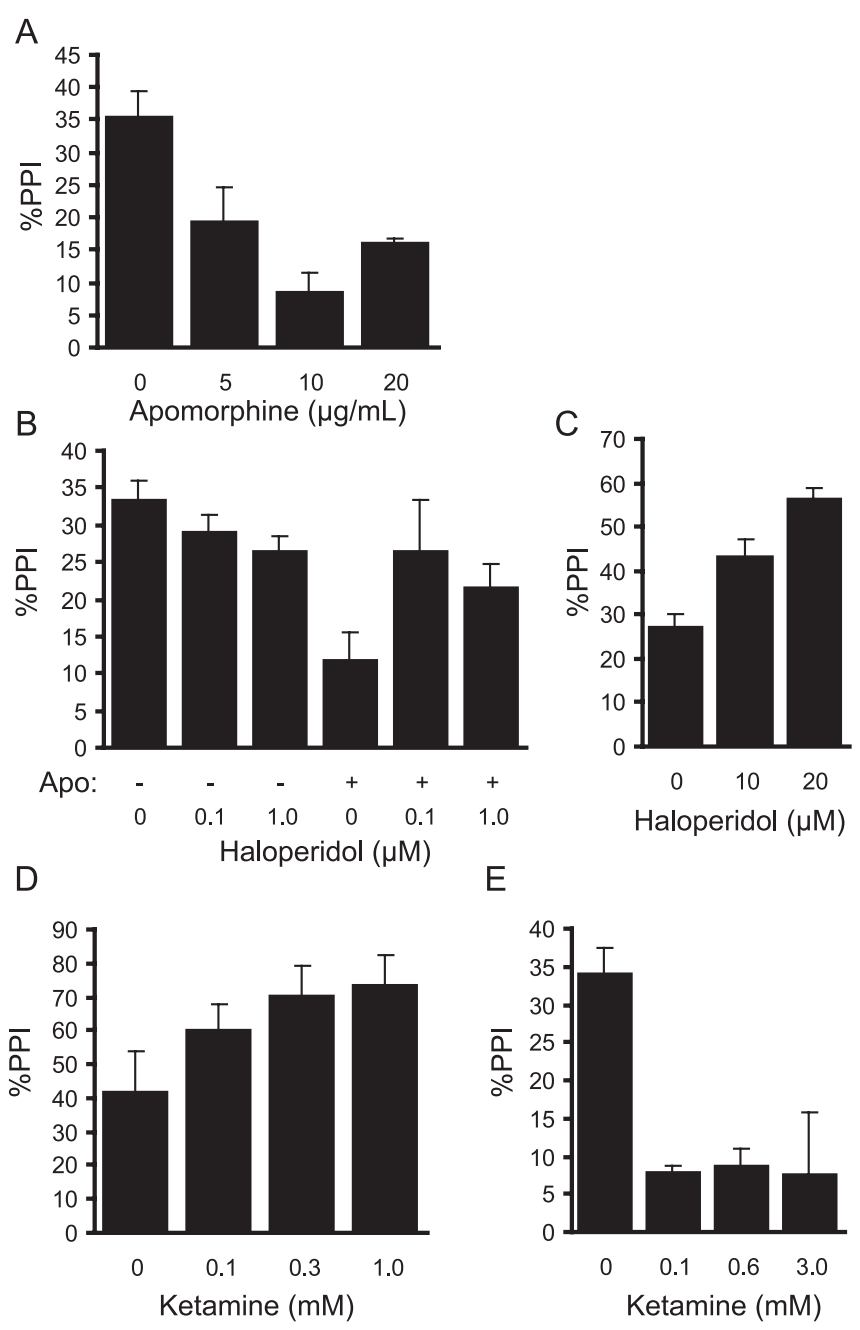

Figure 6. Dopaminergic and glutamatergic drugs modulate PPI in larval zebrafish. $\boldsymbol{A}$, The mixed D1/D2 agonist apomorphine suppresses PPI in $6 \mathrm{dpf}$ zebrafish larvae when added to the medium 10 min before testing $\left(F_{(3,13)}=10.3 ; p=9.6 \times 10^{-4} ; n=4\right.$ for each group except control, $n=5$ ). $\boldsymbol{B}$, Pretreatment of larva, 20 min before testing, with either 0.1 or $1.0 \mu \mathrm{m}$ of the D2 antagonist haloperidol has no significant effect on PPI, but does block the disruption of PPI by apomorphine (two-factor ANOVA gives significant apomorphine by haloperidol interaction, $F_{(2,35)}=3.3, p=0.03 ; n=6$ for each group). C, At higher concentrations (10 and $\left.20 \mu \mathrm{m}\right)$, haloperidol enhances baseline PPI $\left(F_{(2,21)}=21.8 ; p=7.6 \times 10^{-6} ; n=8\right.$, each group). $\boldsymbol{D}$, The NMDA receptor antagonist ketamine augments PPI when the prepulse is given 30 ms before the startle stimulus $\left(F_{(3,22)}=15.5 ; p=1.2 \times 10^{-5} ; n=6\right.$ for each group except control, $\left.n=8\right)$. $\boldsymbol{E}$, Ketamine disrupts PPI at 500 ms interstimulus interval $\left(F_{(3,20)}=8.3 ; p=8.7 \times 10^{-4} ; n=\right.$ 6 , each group). Error bars indicate mean percent $\mathrm{PPI} \pm \mathrm{SEM}$.

contrast, only 3\% (3 of 97) of larvae from sibling parents have similarly low PPI (Fig. $7 A$, top).

PPI deficits can be reliably reidentified in mutants. When larvae in clutches derived from ophelia heterozygotes are tested on day 5 and retested on day 6 , PPI scores for individual larvae show highly significant correlation (Spearman's $r=0.655 ; n=20 ; p=$
0.002) (supplemental Fig. 2, available at www.jneurosci.org as supplemental material). In contrast, no correlation is seen for the day 5 and day 6 PPI scores for larvae derived from sibling parents (Spearman's $r=0.095 ; n=28 ; p=0.63$ ), reflecting the absence of a significant genotypic influence on PPI in these fish. Moreover, mutant larvae identified in this manner show significantly less inhibition across a range of prepulse intensities (Fig. $7 B$ ) (two-way ANOVA, main effect of genotype, $F_{(1,149)}=34.5, p<$ 0.001; main effect of prepulse intensity, $F_{(2,149)}=57.6, p<0.001$; no significant interaction). This confirms that individual mutants can be reliably sorted for molecular genetic mapping and excludes nonspecific developmental delay as the cause of the phenotype.

In addition to having inflated swim bladders, well formed otic vesicles, and normal hair cell morphology (Fig. 7C) (data not shown), mutants show near identical SLC responsiveness to both the startle stimulus $(85 \pm 3.4 \%$ mutants, $82 \pm 3.0 \%$ siblings; $p=$ 0.46 , two-tailed $t$ test) and LLC responses to weak acoustic stimuli (Fig. 7D) (two-way ANOVA, main effect of stimulus intensity, $F_{(2,89)}=25.6, p<0.001$; no main effect of genotype or interaction). It is therefore unlikely that ophelia mutants have reduced sensory acuity. Rather, these observations argue that ophelia mutants have a specific defect in sensorimotor gating. This line represents the first mutant in prepulse inhibition to be recovered from a genetic screen.

\section{Discussion}

These results demonstrate for the first time a form of sensorimotor gating of the startle response in zebrafish, with distinct similarities to prepulse inhibition in mammals. Prepulse inhibition of the startle response has been characterized in the mollusk Tritonia diomedea (Mongeluzi et al., 1998), whose simple nervous system made feasible the elucidation of a cellular basis for the phenomenon (Frost et al., 2003). The only previous description of prepulse inhibition in a nonmammalian vertebrate has been in the pigeon, in which prepulse inhibition exhibits similar parametric and pharmacological characteristics to that in higher vertebrates (Stitt et al., 1976; Schall et al., 1999). The fact that prepulse inhibition is observed in zebrafish shortly after hatching supports the contention that prepulse inhibition of startle represents a phylogenetically ancient and basic mode of behavioral plasticity.

To characterize PPI, we first needed to quantitatively define the normal repertoire of responses to acoustic stimuli in larval zebrafish. We found two modes of response: short latency C-start responses and long latency C-start responses. SLCs are highperformance responses mediated by the Mauthner cell, whereas LLC responses have slower kinematics and are unaffected by Mauthner cell ablation. SLCs are an all-or-nothing response, independent of stimulus intensity. In contrast, LLC responses are unaffected by Mauthner cell ablation and are graded in magnitude according to stimulus intensity. The short latency, kinematics, and Mauthner dependence of acoustic SLC responses resemble responses described previously in larval zebrafish using tail- 
touch stimuli (O’Malley et al., 1996; Liu and Fetcho, 1999) and vibrational stimuli (Kimmel et al., 1980). In contrast to previous work (Kimmel et al., 1980), we found no evidence that non-Mauthner circuits can mediate "fast-start" responses in zebrafish larvae. After Mauthner ablation, the only instances we saw in which SLC responses were initiated contralateral to the ablated cell involved larvae with their head contacting the edge of their chamber. This is consistent with evidence that short-latency responses to head directed stimuli are mediated not only by the Mauthner cells, but by two pairs of segmental homologs (Liu and Fetcho, 1999). The fact that we did not observe non-Mauthner fast-start responses may reflect differences in the sensory modality activated by the acoustic stimulus we used.

The LLCs characterized in this report differ from previously described longlatency responses in zebrafish larvae. Long-latency "type I" responses first described by Kimmel et al. (1974) (Eaton and Farley, 1975) involve neither vigorous C-bends nor swim bursts. The latency and reduced performance of LLCs most resemble that of startle responses in zebrafish larvae after Mauthner cell or array ablation (Kimmel et al., 1980; Liu and Fetcho, 1999). However, previous reports of non-Mauthner responses to startle stimuli in zebrafish larvae do not have the extended latency of LLCs (Eaton and Kimmel, 1980), whereas non-Mauthner responses in goldfish have been described as being kinematically similar to SLCs (Zottoli et al., 1999). Because LLCs were observed at a similar frequency when larvae were tested individually, we can exclude the possibility that our observations are an artifact of group testing. Rather, poor temporal resolution of SLCs and LLCs at low frame rates, the small number of responses analyzed in previous studies, and the use of intense stimuli that preferentially elicit SLCs may explain why long-latency C-bends in wildtype zebrafish larvae have been overlooked until now. Notably, long-latency, reduced performance C-starts resembling LLCs, have been proposed to facilitate coordinated escape in schooling herring (Domenici and Batty, 1994, 1997), providing an intriguing clue to their behavioral function. Under the stimulus conditions we tested, movement trajectories for SLCs and LLCs were almost identical and we were unable to detect any significant directional bias to responses relative to the stimulus. Future experiments using acoustic stimuli with well defined points of origin will address the hypothesis that the longer latency of LLCs provides sufficient time to integrate positional information and produce directional responses. Zebrafish larvae occasionally exhibit a third mode of response involving multiple tail flips to extremely intense stimuli (Kimmel et al., 1974). These responses were not observed in this study, probably because of the use of relatively moderate stimulus intensities.

SLC responses in zebrafish are modulated by weak prepulses in a manner similar to prepulse inhibition in higher vertebrates. The key difference between mammalian prepulse inhibition and
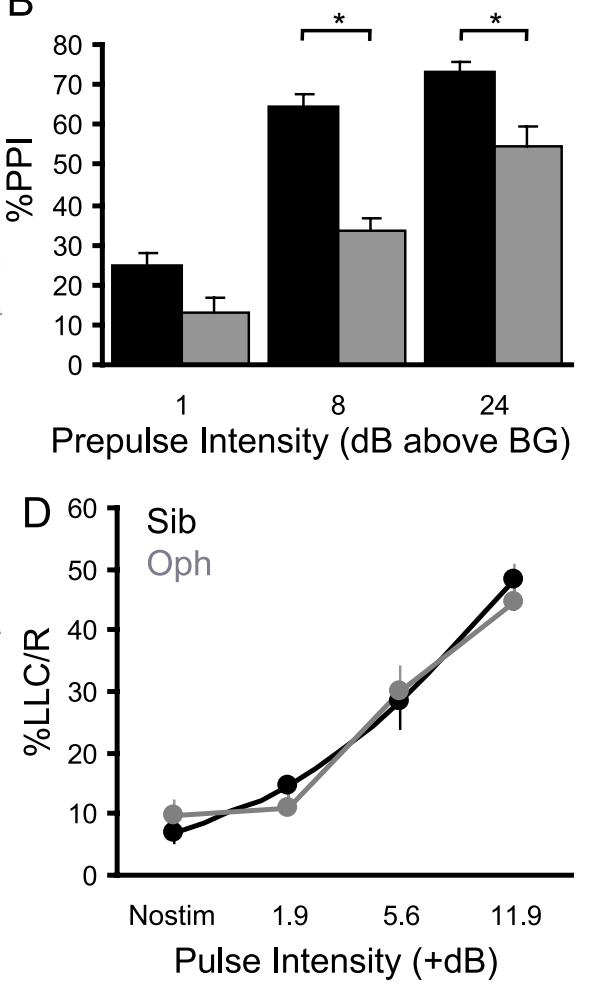

mut

sib
B

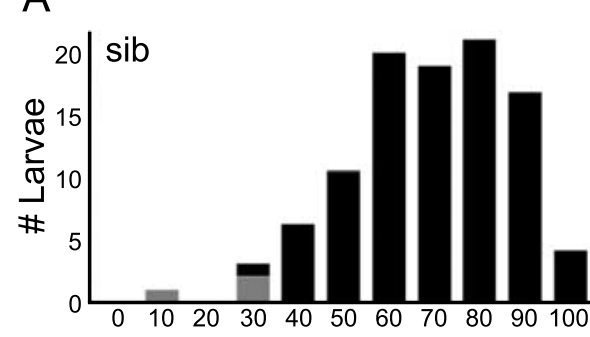

1

Figure 7. Reduced PPI in ophelia mutant larvae. $\boldsymbol{A}$, Distribution of percent PPI among larvae in an ophelia mutant clutch compared with larvae from a wild-type sibling clutch. In a wild-type clutch (top), PPI was $64.0 \pm 17.8 \%$ (mean \pm SD). Only 3 of 源 (Oph) and siblings show identical levels of spontaneous activity (Nostim) and LLC responsiveness to weak pulses. Error bars indicate mean percent PPI \pm SEM. sib, Sibling; mut, mutant.

the inhibition described here is that in mammals, PPI reduces the magnitude of the response, whereas weak prepulses reduce the probability of eliciting an SLC in zebrafish. We believe that this is consistent with SLCs being all-or-nothing responses dependent on Mauthner cell activity. In mammals, the magnitude of the startle response is determined by the fraction of the thousands of neurons in the pontine reticular nucleus caudal (PNc) activated by the startle stimulus (Lingenhohl and Friauf, 1994; Koch, 1999). PPI attenuates the magnitude of the startle response by reducing the fraction of $\mathrm{PNc}$ neurons activated. Because only two Mauthner neurons are available to initiate the SLC response in larvae, it is not surprising that the effect of PPI is to reduce the probability of executing a short-latency startle, rather than to attenuate its magnitude. Indeed, in humans, eyeblink responses to low-intensity acoustic stimuli are probabilistic (Blumenthal and Goode, 1991; Dahmen and Corr, 2004), although these responses may not represent authentic startles (Swerdlow et al., 2004; Yee et al., 2004).

Two lines of evidence support the argument that prepulse inhibition in fish is homologous to PPI in higher vertebrates. First, the effective interstimulus interval for inhibition in fish is comparable with previously reported effective lead intervals in humans (Braff et al., 1978), rats (Parisi and Ison, 1979; Mansbach and Geyer, 1991), and primates (Javitt and Lindsley, 2001). Second, as in higher vertebrates, prepulse inhibition in fish is modulated by dopaminergic and glutamatergic drugs. Notably, a conserved role for dopamine in regulating PPI was suggested 
previously by disruption of PPI in pigeons by apomorphine and amphetamine (Schall et al., 1999). Although teleost fish lack midbrain dopamine sources, the ascending projection from the posterior tubercle to the ventral telencephalic area has been proposed to be analogous to the mammalian mesolimbic pathway (Rink and Wullimann, 2002). Moreover, as in mice, where augmentation of dopamine availability in the nucleus accumbens is sufficient to confer hyperlocomotive behavior (Heusner et al., 2003), the dopamine agonist apomorphine induces hyperlocomotion in adult goldfish (Mok and Munro, 1998). Likewise, we found that apomorphine strongly potentiates spontaneous swimming in 6 dpf zebrafish (data not shown), arguing that a mesolimbic-like circuit is already functional in these animals.

Intrinsic intertrial and interindividual variability often confounds the reliable quantification of animal behavior. Here, we use a novel automated tracking system to describe stimulus response patterns based on thousands of trials, dramatically enhancing the power of statistical analysis. Together with the ease of obtaining large numbers of embryos, this makes it possible to undertake a systematic analysis of behavior and to rapidly test the effect of drugs on startle modulation. Indeed, we demonstrate that both apomorphine and ketamine impair prepulse inhibition in fish, providing a compelling parallel to standard assays for the efficacy of antipsychotic compounds in mammals. The same assay enabled us to isolate genetic mutants with specific deficits in PPI. Analysis of mutants obtained from genetic screens have yielded striking insights into the molecular and cellular basis of sensorimotor integration in Caenorhabditis elegans (Tsalik and Hobert, 2003; Gray et al., 2005). Our data demonstrate the feasibility of a similar approach to elucidate the neural circuitry mediating prepulse inhibition in fish. The existence of a form of startle modulation with paradigmatic features and pharmacological sensitivity similar to PPI in mammals, makes larval zebrafish a powerful system by which to study the mechanistic basis of a behavior relevant to human neurological disorders.

\section{References}

Abel KM, Allin MP, Hemsley DR, Geyer MA (2003) Low dose ketamine increases prepulse inhibition in healthy men. Neuropharmacology 44:729-737.

Anholt RR, Mackay TF (2004) Quantitative genetic analyses of complex behaviours in Drosophila. Nat Rev Genet 5:838-849.

Anokhin AP, Heath AC, Myers E, Ralano A, Wood S (2003) Genetic influences on prepulse inhibition of startle reflex in humans. Neurosci Lett 353:45-48.

Blumenthal TD, Goode CT (1991) The startle eyeblink response to low intensity acoustic stimuli. Psychophysiology 28:296-306.

Blumenthal TD, Elden A, Flaten MA (2004) A comparison of several methods used to quantify prepulse inhibition of eyeblink responding. Psychophysiology 41:326-332.

Braff D, Stone C, Callaway E, Geyer M, Glick I, Bali L (1978) Prestimulus effects on human startle reflex in normals and schizophrenics. Psychophysiology 15:339-343.

Braff DL, Geyer MA, Swerdlow NR (2001) Human studies of prepulse inhibition of startle: normal subjects, patient groups, and pharmacological studies. Psychopharmacology (Berl) 156:234-258.

Castellanos FX, Fine EJ, Kaysen D, Marsh WL, Rapoport JL, Hallett M (1996) Sensorimotor gating in boys with Tourette's syndrome and ADHD: preliminary results. Biol Psychiatry 39:33-41.

Crocker J, Grier D (1996) Methods of digital video microscopy for colloidal studies. J Colloid Interface Sci 179:298-310.

Currie S, Carlsen R (1987) Modulated vibration-sensitivity of lamprey Mauthner neurones. J Exp Biol 129:41-51.

Curzon P, Decker MW (1998) Effects of phencyclidine (PCP) and (+)MK801 on sensorimotor gating in CD-1 mice. Prog Neuropsychopharmacol Biol Psychiatry 22:129-146.
Dahmen JC, Corr PJ (2004) Prepulse-elicited startle in prepulse inhibition. Biol Psychiatry 55:98-101.

Dawson ME, Schell AM, Bohmelt AH (1999) Startle modification, implications for neuroscience, cognitive science and clinical science, Ed 1. Cambridge, UK: Cambridge UP.

Depoortere R, Perrault G, Sanger D (1997) Potentiation of prepulse inhibition of the startle reflex in rats: pharmacological evaluation of the procedure as a model for detecting antipsychotic activity. Psychopharmacology 132:366-374.

Domenici P, Batty R (1994) Escape manoeuvres of schooling Clupea harengus. J Fish Biol 45:97-110.

Domenici P, Batty R (1997) Escape behaviour of solitary herring (Clupea harengus) and comparisons with schooling individuals. Mar Biol 128:29-38.

Dosch R, Wagner DS, Mintzer KA, Runke G, Wiemelt AP, Mullins MC (2004) Maternal control of vertebrate development before the midblastula transition: mutants from the zebrafish I. Dev Cell 6:771-780.

Duncan EJ, Madonick SH, Parwani A, Angrist B, Rajan R, Chakravorty S, Efferen TR, Szilagyi S, Stephanides M, Chappell PB, Gonzenbach S, Ko GN, Rotrosen JP (2001) Clinical and sensorimotor gating effects of ketamine in normals. Neuropsychopharmacology 25:72-83.

Eaton R, Farley R (1975) Mauthner neuron field potential in newly hatched larvae of the zebra fish. J Neurophysiol 38:502-512.

Eaton R, Kimmel C (1980) Directional sensitivity of the Mauthner cell system to vibrational stimulation in zebrafish larvae. J Comp Physiol A Neuroethol Sens Neural Behav Physiol 140:337-342.

Eaton R, Lavender W, Wieland C (1981) Identification of Mauthnerinitiated response patterns in goldfish: evidence from simultaneous cinematography and electrophysiology. J Comp Physiol A Neuroethol Sens Neural Behav Physiol 144:521-531.

Eaton RC, DiDomenico R, Nissanov J (1991) Role of the Mauthner cell in sensorimotor integration by the brain stem escape network. Brain Behav Evol 37:272-285.

Frost WN, Tian LM, Hoppe TA, Mongeluzi DL, Wang J (2003) A cellular mechanism for prepulse inhibition. Neuron 40:991-1001.

Gahtan E, Sankrithi N, Campos JB, O’Malley DM (2002) Evidence for a widespread brain stem escape network in larval zebrafish. J Neurophysiol 87:608-614.

Geyer MA, Krebs-Thomson K, Braff DL, Swerdlow NR (2001) Pharmacological studies of prepulse inhibition models of sensorimotor gating deficits in schizophrenia: a decade in review. Psychopharmacology (Berl) 156:117-154.

Geyer MA, McIlwain KL, Paylor R (2002) Mouse genetic models for prepulse inhibition: an early review. Mol Psychiatry 7:1039-1053.

Goldsmith P (2004) Zebrafish as a pharmacological tool: the how, why and when. Curr Opin Pharmacol 4:504-512.

Gray JM, Hill JJ, Bargmann CI (2005) A circuit for navigation in Caenorhabditis elegans. Proc Natl Acad Sci USA 102:3184-3191.

Hatta K (1992) Role of the floor plate in axonal patterning in the zebrafish CNS. Neuron 9:629-642.

Heusner CL, Hnasko TS, Szczypka MS, Liu Y, During MJ, Palmiter RD (2003) Viral restoration of dopamine to the nucleus accumbens is sufficient to induce a locomotor response to amphetamine. Brain Res 980:266-274.

Javitt DC, Lindsley RW (2001) Effects of phencyclidine on prepulse inhibition of acoustic startle response in the macaque. Psychopharmacology (Berl) 156:165-168.

Jones G, Milicich M, Emslie M, Lunow C (1999) Self-recruitment in a coral reef fish population. Nature 402:802-804.

Joober R, Boksa P, Benkelfat C, Rouleau G (2002) Genetics of schizophrenia: from animal models to clinical studies. J Psychiatry Neurosci $27: 336-347$.

Kimmel C, Eaton R, Powell S (1980) Decreased fast-start performance of zebrafish larvae lacking Mauthner neurons. J Comp Physiol A Neuroethol Sens Neural Behav Physiol 140:343-350.

Kimmel CB, Patterson J, Kimmel RO (1974) The development and behavioral characteristics of the startle response in the zebra fish. Dev Psychobiol 7:47-60.

Kingsford M, Leis J, Shanks A, Lindeman K, Morgan S, Pineda J (2002) Sensory environments, larval abilities and local self-recruitment. Bull Marine Sci 70:309-340.

Koch M (1999) The neurobiology of startle. Prog Neurobiol 59:107-128. 
Kumari V, Soni W, Sharma T (1999) Normalization of information processing deficits in schizophrenia with clozapine. Am J Psychiatry 156:1046-1051.

Laruelle M, Kegeles LS, Abi-Dargham A (2003) Glutamate, dopamine, and schizophrenia: from pathophysiology to treatment. Ann NY Acad Sci 1003:138-158.

Lingenhohl K, Friauf E (1994) Giant neurons in the rat reticular formation: a sensorimotor interface in the elementary acoustic startle circuit? J Neurosci 14:1176-1194.

Linn GS, Javitt DC (2001) Phencyclidine (PCP)-induced deficits of prepulse inhibition in monkeys. NeuroReport 12:117-120.

Linn GS, Negi SS, Gerum SV, Javitt DC (2003) Reversal of phencyclidineinduced prepulse inhibition deficits by clozapine in monkeys. Psychopharmacology (Berl) 169:234-239.

Liu KS, Fetcho JR (1999) Laser ablations reveal functional relationships of segmental hindbrain neurons in zebrafish. Neuron 23:325-335.

Mansbach R, Geyer M (1989) Effects of phencyclidine and phencyclidine biologs on sensorimotor gating in the rat. Neuropsychopharmacology 2:299-308.

Mansbach RS, Geyer MA (1991) Parametric determinants in pre-stimulus modification of acoustic startle: interaction with ketamine. Psychopharmacology (Berl) 105:162-168.

Mansbach RS, Geyer M, Braff D (1988) Dopaminergic stimulation disrupts sensorimotor gating in the rat. Psychopharmacology 94:507-514.

Mok EY, Munro AD (1998) Effects of dopaminergic drugs on locomotor activity in teleost fish of the genus Oreochromis (Cichlidae): involvement of the telencephalon. Physiol Behav 64:227-234.

Mongeluzi DL, Hoppe TA, Frost WN (1998) Prepulse inhibition of the Tritonia escape swim. J Neurosci 18:8467-8472.

Mullins MC, Hammerschmidt M, Haffter P, Nusslein-Volhard C (1994) Large-scale mutagenesis in the zebrafish: in search of genes controlling development in a vertebrate. Curr Biol 4:189-202.

O’Malley DM, Kao YH, Fetcho JR (1996) Imaging the functional organization of zebrafish hindbrain segments during escape behaviors. Neuron 17:1145-1155.

Ouagazzal A, Jenck F, Moreau J (2001) Drug-induced potentiation of prepulse inhibition of acoustic startle reflex in mice: a model for detecting antipsychotic activity? Psychopharmacology 156:273-283.

Parisi T, Ison JR (1979) Development of the acoustic startle response in the rat: ontogenetic changes in the magnitude of inhibition by prepulse stimulation. Dev Psychobiol 12:219-230.

Preuss T, Faber DS (2003) Central cellular mechanisms underlying temperature-dependent changes in the goldfish startle-escape. Behav J Neurosci 23:5617-5626.

Putnam LE, Vanman EJ (1999) Long lead interval startle modification. In: Startle modification, implications for neuroscience, cognitive science and clinical science (Dawson ME, Schell AM, Bohmelt AH, eds), pp 72-92. Cambridge, UK: Cambridge UP.

Ralph-Williams RJ, Lehmann-Masten V, Geyer MA (2003) Dopamine D1 rather than D2 receptor agonists disrupt prepulse inhibition of startle in mice. Neuropsychopharmacology 28:108-118.
Rink E, Wullimann MF (2002) Connections of the ventral telencephalon and tyrosine hydroxylase distribution in the zebrafish brain (Danio rerio) lead to identification of an ascending dopaminergic system in a teleost. Brain Res Bull 57:385-387.

Schall U, Keysers C, Kast B (1999) Pharmacology of sensory gating in the ascending auditory system of the pigeon (Columba livia). Psychopharmacology (Berl) 145:273-282.

Sokolowski MB (2001) Drosophila: genetics meets behaviour. Nat Rev Genet 2:879-890.

Stitt CL, Hoffman HS, Marsh RR, Schwartz GM (1976) Modification of the pigeon's visual startle reaction by the sensory environment. J Comp Physiol Psychol 90:601-619.

Swearer S, Caselle J, Lea D, Warner R (1999) Larval retention and recruitment in an island population of a coral-reef fish. Nature 402:799-802.

Swerdlow NR, Geyer MA (1999) Neurophysiology and neuropharmacology of short lead interval startle modification. In: Startle modification, implications for neuroscience, cognitive science and clinical science (Dawson ME, Schell AM, Bohmelt AH, eds), pp 114-133. Cambridge, UK: Cambridge UP.

Swerdlow NR, Braff D, Taaid N, Geyer M (1994) Assessing the validity of an animal model of deficient sensorimotor gating in schizophrenic patients. Arch Gen Psychiatry 51:139-154.

Swerdlow NR, Paulsen J, Braff DL, Butters N, Geyer MA, Swenson MR (1995) Impaired prepulse inhibition of acoustic and tactile startle response in patients with Huntington's disease. J Neurol Neurosurg Psychiatry 58:192-200.

Swerdlow NR, Geyer MA, Braff DL (2001) Neural circuit regulation of prepulse inhibition of startle in the rat: current knowledge and future challenges. Psychopharmacology (Berl) 156:194-215.

Swerdlow NR, Talledo J, Shoemaker JM, Codon K, Goins J, Auerbach PP (2004) Weak prepulses inhibit but do not elicit startle in rats and humans. Biol Psychiatry 55:1195-1198.

Tsalik EL, Hobert O (2003) Functional mapping of neurons that control locomotory behavior in Caenorhabditis elegans. J Neurobiology 56:178-197.

Whitfield T, Granato M, van Eeden F, Schach U, Brand M, Furutani-Seiki M, Haffter P, Hammerschmidt M, Heisenberg C, Jiang Y, Kane D, Kelsh R, Mullins M, Odenthal J, Nusslein-Volhard C (1996) Mutations affecting development of the zebrafish inner ear and lateral line. Development 123:241-254.

Yee BK, Russig H, Feldon J (2004) Apomorphine-induced prepulse inhibition disruption is associated with a paradoxical enhancement of prepulse stimulus reactivity. Neuropsychopharmacology 29:240-248.

Zottoli SJ, Bentley AP, Prendergast BJ, Rieff HI (1995) Comparative studies on the Mauthner cell of teleost fish in relation to sensory input. Brain Behav Evol 46:151-164.

Zottoli SJ, Newman BC, Rieff HI, Winters DC (1999) Decrease in occurrence of fast startle responses after selective Mauthner cell ablation in goldfish (Carassius auratus). J Comp Physiol A Neuroethol Sens Neural Behav Physiol 184:207-218. 